\title{
Fire Spread of Urban Area at the Kobe Earthquake
}

\author{
YOSHIRO NAMBA, KENJIRO YASUNO and TADAHIKO NISHITANI \\ Department of Architecture \\ Kinki University \\ 1-Takayaumenobe, Higashi hiroshima, Hiroshima, 739-21, Japan
}

\begin{abstract}
The several that many fires occurred simultaneously at the time of the Kobe earthquake in 1995 became urban area fires. Thereupon, we analyzed the fire spread situation of urban area fires of Kobe city in this research. We used the data that was obtained by Fire Department of Kobe city and Tokyo Fire Department. The fire data that we analyzed has over about 10,000 $\mathrm{m}^{2}$ of burn-out area . It is as a future research theme about the fire spread condition which fire fighting water is considered. The fire spread model that considered burn-out area, fire front length and also the fire spread speed, were examined in this paper.
\end{abstract}

KEYWORDS: fire spread, fire front length, urban area, the Kobe earthquake, burn-out area

\section{INTRODUCTION}

There are several researches of the fire spread speed formulas such as Hamada[1], Horiuchi[2], Yasuno/Namba[3-11], Tokyo fire department[12],Itoigawa[13] and so forth. Here, we explain about the model of authors that has applied for the usual fire.

First of all we thought a polynomial expression as a relation between burn-out area (A: $\left.\mathrm{m}^{2}\right)$ and time $(\mathrm{x}: \mathrm{min})$. When the degree of a polynomial expression was analyzed by a method called MAICE (Minimum AIC Estimation[14]) by using the fire experiments of data of Saganoseki real house group [15], it was understood that 3-degree equation is proper. MAICE is a statistical method that may be use when we decide the number of degree of a regression equation[16]. The statistic model that a value of AIC (Akaike information criteria) becomes minimum is optimum. By the way, it should be a monotonous increase function for a nature of expression from a viewpoint of fire phenomenon. However, there are some cases that it is not possible to satisfy this nature by a polynomial expression. Thereupon, we have proposed an application of a logistic curve as the representative 
function of $\mathrm{S}$ curve of the monotonous increase function. Parameters of a logistic curve is the same number as 3-degree equation. Furthermore, it was understood that the logistic curve was matched by the data than 3-degree equation when sum square of residual was compared. The logistic curve as shown in eq.(1) is an nonlinear form regarding with parameters. Accordingly, initial values need to be given to parameters in order to calculate. And there are some cases that do not converge. However, each parameters can be gotten with quite a lot accuracy by the graphical method[5]. Substituting these values in eq.(1), each value can be gotten by the nonlinear least square method. On the other hand, the logistic curve is a solution curve of the self catalyst reaction equation in a simple molecule catalyst reaction. It seems good as the fire spread model from resemblance nature of the diagram. In other words, the relation among burn-out area $\left(A: \mathrm{m}^{2}\right)$, architecture area $\left(\mathrm{G}: \mathrm{m}^{2}\right)$ and also time $(\mathrm{x}: \mathrm{min})$ is indicate as $\mathrm{dA} / \mathrm{dx}=\lambda(\mathrm{G}-\mathrm{A}) \mathrm{A}$, where, $\lambda$ is a proportion constant. And we can integrate this equation, putting with $\lambda \mathrm{G}=\mathrm{a}$. Making burnt-out time $\mathrm{x}_{\mathrm{G}}(\mathrm{min})$, the model that satisfied the boundary conditions as $A=0$ at the time of $x=0$ and also $A=G$ at the time of $x=x_{G}$ is eq.(1). We have grasped the situation that a top of fire is going to spread from the point of fire-outbreak like this. In other words, the fire spread model equation of a wooden building of the fire spread process of the case that does not accompany a fire fighting activity becomes generally S curve like real line of FIGURE 1. The fire spread model that substituted from eq.(1-a) to eq.(1-f) in eq.(1) can express as the usual real urban fire in Japan.

$$
\begin{aligned}
& A=\frac{G+n \cdot \varepsilon}{1+\exp \left\{-a_{1} \cdot\left(x-c_{1}\right)\right\}}-\frac{G+n \cdot \varepsilon}{1+\exp \left(a_{1} \cdot c_{1}\right)} \\
& n=\left(1.39-2.82 \times 10^{-4} G\right) \times \exp \left\{\left(5.16 \times 10^{-2}+3.29 \times 10^{-4} G-2.18 \times 10^{-7} G^{2}\right) v\right\} \\
& \varepsilon=\frac{G}{1+\exp (a \cdot c)} \\
& a=\left(0.175+0.0245 v^{1.62}\right)\left(\frac{176}{G}\right)^{0.582 \exp (-0.146 v)} \\
& c=\frac{\log _{e}\left(0.980 a^{1.40} G\right)}{a} \\
& a_{1}=\left(0.175+0.0245 v^{1.62}\right)\left(\frac{176}{G+n \cdot \varepsilon}\right)^{0.582 \exp (-0.146 v)} \\
& c_{1}=\frac{\log _{e}\left\{0.980 a_{1}^{1.40}(G+n \cdot \varepsilon)\right\}}{a_{1}}
\end{aligned}
$$

where, A : burn-out area $\left(\mathrm{m}^{2}\right), \quad \mathrm{x}$ : progress time from outbreak of fire (min), $\mathrm{G}$ : architecture area of a house ( or architecture area of a building group, $A \leqq G$ ), v: wind velocity $(\mathrm{m} / \mathrm{s}), \mathrm{n}$ : coefficient; generally, it becomes about $1.3<\mathrm{n}<2$. 


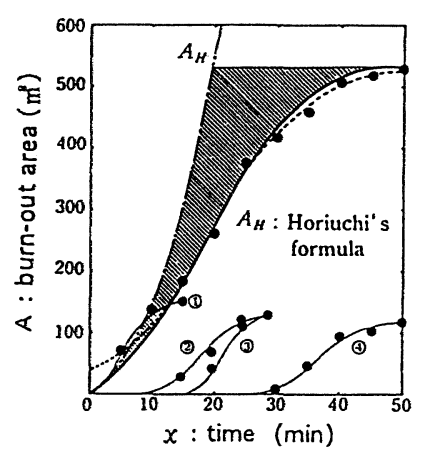

FIGURE 1 Comparison with burn-out area of houses (1) (4)) and that of summing up by the fire experiments of real house groups of Saganoseki and a fire spread speed formula eq.(1) and also a Horiuchi formula $\left(\mathrm{A}_{\mathrm{H}}\right)$

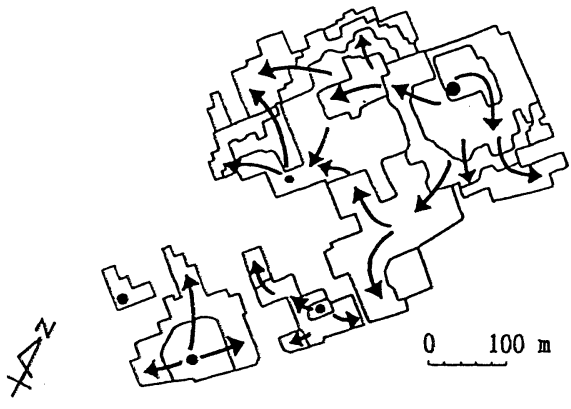

FIGURE 2 Fire spread movement figures of Survey area 1[19]

Each coefficient $\mathrm{n}, \varepsilon, \mathrm{a}, \mathrm{c}, \mathrm{a}_{1}$ and $\mathrm{c}_{1}$ from eq.(1-a) to eq.(1-f) was gotten from the usual real fire data of $\mathrm{K}$ city. Application ranges of eq.(1) are $0 \leqq \mathrm{v} \leqq 10 \mathrm{~m} / \mathrm{s}, 50 \leqq \mathrm{G} \leqq 1500$ $\mathrm{m}^{2}, \mathrm{x} \leqq 90 \mathrm{~min}$, average building-to-land ratio from 50 to $60 \%$ to use well accuracy . Also, as it understands from eq. $(1)$ that $\left(\mathrm{G} \rightarrow\right.$ large, $\mathrm{a}_{1} \rightarrow$ small $),\left(\mathrm{v} \rightarrow\right.$ large, $\mathrm{a}_{1} \rightarrow$ large $)$ and $\left(\mathrm{a}_{1} \rightarrow\right.$ large, $c_{1} \rightarrow$ small). There are some cases that become $A_{1}>A_{2}$ in spite of $G_{1}<G_{2}$ in an early period. In those cases, because this is conceivable as the error that appears on a nature of curve, it makes it a rule to use such case as $A_{2}=A_{1}$. One point chain line of FIGURE 1 is a curve of the case that suppresses it by discharge activities for three units of fire fighting pump automobile in Japan.

As an example, each logistic curve from (1) to (4) and the whole and also a model of Horiuchi $\left(\mathrm{A}_{\mathrm{H}}\right)$ are shown to FIGURE 1 as the fire experiment of the Saganoseki real house groups (4 houses) data and the fire spread speed model by authors. The model of Horiuch that transformed Hamada's becomes to decide large like a diagonal part and becomes two degrees expression regarding with time. Like this, eq. (1) matches to building fires of recent Japan for the most part.

Also the fire spread model of the fireproof structure system was obtained from the fire data of Kobe city and this is shown in eq.(2).

$$
\begin{aligned}
& A=\frac{G}{1+\exp \{-a \cdot(x-b)\}} \\
& a=4.36 G^{-0.365} \\
& b=4.98 G^{0.137}
\end{aligned}
$$

where, $\mathrm{x}$ : progress time from outbreaks of fire ( $5 \leqq \mathrm{x} \leqq 90 \mathrm{~min}$ ), G: architecture area of one division or one house $\left(5 \leqq \mathrm{G} \leqq 300 \mathrm{~m}^{2}\right)$. 


\section{DATA TREATMENT}

Large-scale fires are shown like TABLE 1 at the time of the Kobe Earthquake by Fire Department of Kobe city and Tokyo Fire Department. It decided that a line was grasped precisely for the most part at the time of the fire spread as a result of hearing about survey area from 1 to 6 and from 8 to 9. The fire spread movement figure of TABLE 1 is decided that it is under investigation in a present stage about survey area 7,10 and also 11 . It is excluding from the analysis areas with survey area 7,10 and also 11 under surveying at present, because there is a little indistinct point about survey area 9 as a result that each survey area is examined about the fire spread movement figure.

Also, examining the fire spread movement figure regarding each survey area it was analyzed and a partially indistinct place was excluded. Specifically, fire number (5) is making $17,537 \mathrm{~m}^{2}$ in $58,372 \mathrm{~m}^{2}$ an object. Also, it was analyzed as $51,593 \mathrm{~m}^{2}$ in $69,005 \mathrm{~m}^{2}$ about survey area 6 . Furthermore, the burn-out area was included the site and also the street. We would examine based on the survey areas of TABLE 1.

The fire spread movement figure of survey area 1 is shown to FIGURE 2 as a example of TABLE 1. Measuring burn-out area at each time by a computer from these fire spread movement figures, the analysis data was produced. And the relation between burn-out area and time has been solved by the non-linear least square method.

Records of wind velocity at Fire Department of Kobe city (Sannomiya) was used. Average wind velocity was from about 0.0 to $6.1 \mathrm{~m} / \mathrm{s}$ at that day. The building distribution situation figure by the Kobe earthquake disaster damage urgent survey that the City Planning Institute of Japan and also Architectural Institute of Japan investigated the complete collapse rate that shows it here, is the damage of the destruction town ward by fire that was estimated from a periphery town ward. It was shown as the complete collapse rate (complete collapse or serious damage) of building below the 2 nd floor that wooden or the fire prevention wooden building occupies majority. The burn-out area, the average wind velocity and complete collapse rate of each survey area are shown to TABLE 2.

\section{ANALYSYS AND RESULTS}

In this research, fires of the case that is over about $30 \%$ collapsed of wooden, fire prevention wooden and also fireproof structures were analyzed. The result that applied eq.(1) in each survey area here is shown to TABLE 3 . This result has been solved requesting by the least square method. The coefficient of correlation is about 0.98 and it is matching well.

The relation between burn-out area (A: $\left.\mathrm{m}^{2}\right)$ and time (x: min) of survey area 1 is shown to FIGURE 3 as an example. As shown in eq.(1), the burn-out area will be gotten by these each coefficient from TABLE 3 because it is able to calculate by knowing each coefficient of $(\mathrm{G}+\mathrm{n} \cdot \varepsilon), \mathrm{a}_{1}$ and also $\mathrm{c}_{1}$.

The relation between $\mathrm{G}+\mathrm{n} \cdot \varepsilon$ and $(\mathrm{G} / \mathrm{v})$ was analyzed as

$$
\mathrm{G}+\mathrm{n} \cdot \varepsilon=0.431(\mathrm{G} / \mathrm{v})^{1.11} \quad(\mathrm{R}=0.906)
$$


TABLE 1 Burn-out area( by Tokyo Fire Department and Fire Department of Kobe city)

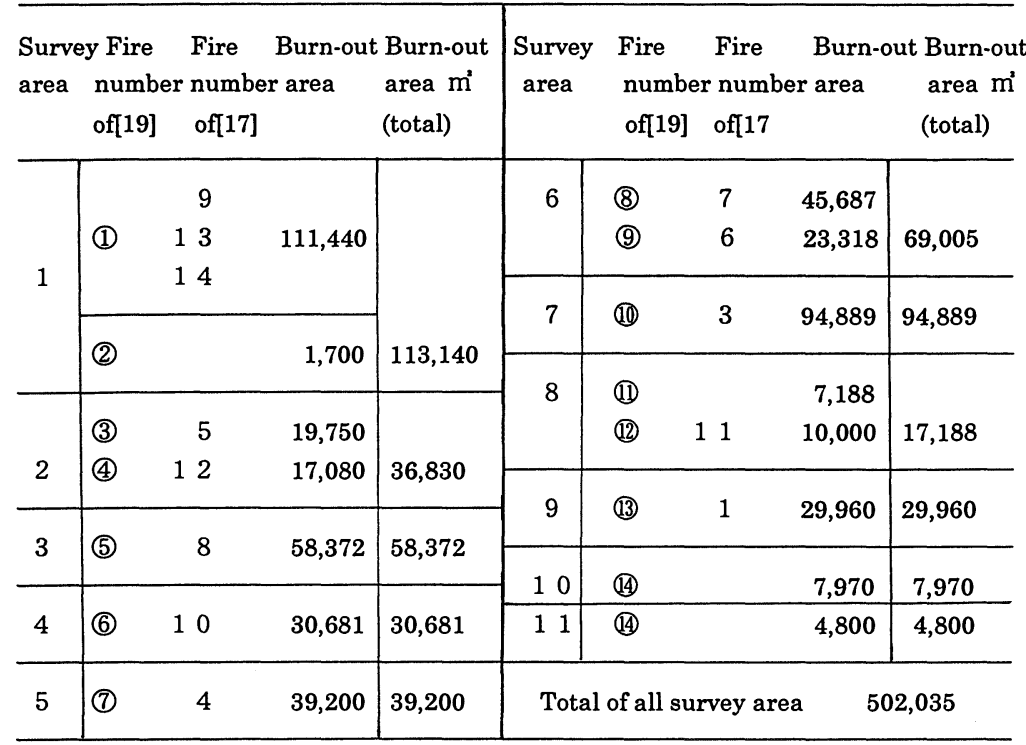

TABLE 2 Burn-out area, average wind velocity and complete collapse rate of each survey area

\begin{tabular}{llll}
\hline $\begin{array}{l}\text { Survey } \\
\text { area }\end{array}$ & $\begin{array}{c}\text { Burn-out } \\
\text { area(m) }\end{array}$ & $\begin{array}{c}\text { Average wind } \\
\text { velocity }(\mathrm{m} / \mathrm{s})\end{array}$ & $\begin{array}{l}\text { Complete collapse } \\
\text { rate of houses }\end{array}$ \\
\hline 1 & 111440 & 1.57 & 0.714 \\
2 & 36830 & 1.18 & 0.667 \\
3 & 17537 & 0.95 & 0.460 \\
4 & 30681 & 1.96 & 0.309 \\
5 & 39200 & 0.89 & 0.485 \\
6 & 51593 & 0.92 & 0.431 \\
8 & 10427 & 1.64 & 0.587 \\
\hline Mean & & 1.30 & \\
\hline
\end{tabular}

where, $10,000<\mathrm{G}<120,000 \mathrm{~m}^{2}$ and wind velocity $\mathrm{v}$ is $0<\mathrm{v}<6 \mathrm{~m} / \mathrm{s}$ by data. The result is shown to FIGURE 4. The coefficient of correlation is 0.906 . Also, it needs to be calculated and needs to be substitute as $\mathrm{v} \fallingdotseq 0.01 \mathrm{~m} / \mathrm{s}$, because it becomes $(\mathrm{G}+\mathrm{n} \cdot \varepsilon) \rightarrow \infty$ in the case of wind velocity $\mathrm{v}=0$ in eq.(3). 


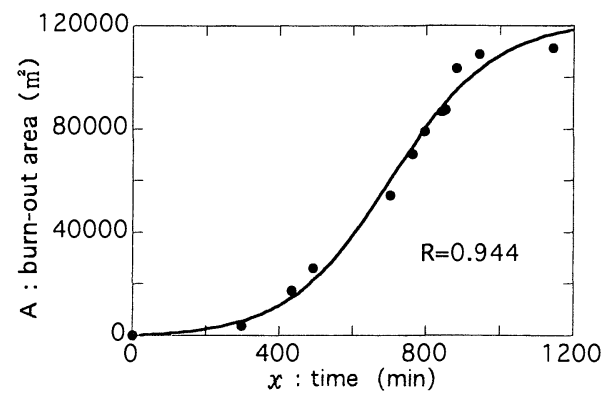

FIGURE 3 Relation between burn-out area and time of survey area 1

Furthermore, although $\mathrm{n} \cdot \varepsilon$ is calculated by substituting $\mathrm{G}$ and also $\mathrm{v}$ of TABLE 3 in eq.(3), $n \cdot \varepsilon=0$ is made if it becomes $n \cdot \varepsilon<0$, because it shall be $n \cdot \varepsilon \geqq 0$. For instance, because it is $\mathrm{G}=111,440 \mathrm{~m}^{2}, \mathrm{v}=1.57 \mathrm{~m} / \mathrm{s}$ from TABLE 3 in the case of survey area 1 , it is calculated with $(\mathrm{G}+\mathrm{n} \varepsilon)=103,314, \mathrm{n} \cdot \varepsilon=-8,125$. Therefore, it needs to be made $(\mathrm{G}+\mathrm{n} \cdot$ $\varepsilon)=\mathrm{G}=111,440 \mathrm{~m}^{2}$.

Considering the complete collapse rate (D) from eq.(1) about a 1 , it is able to indicate as a function of (1-D) $v / G$. The result is shown to FIGURE 5. R as shown in eq. (4) is 0.973 and it is a fairly good correlation. In the case of wind velocity $\mathrm{v}=0$, it needs to calculate as the wind velocity $\mathrm{v} \fallingdotseq 0.01 \mathrm{~m} / \mathrm{s}$ similarly of $(\mathrm{G}+\mathrm{n} \cdot \varepsilon)$.

$a_{1}=2.28 \times 10^{20}\left\{\frac{(1-D) \cdot v}{G}\right\}^{5.17}+0.0114 \quad(\mathrm{R}=0.973)$

where, $\mathrm{D}$ is the value of complete collapse rate as a range about $0.3<\mathrm{D}<0.7$.

Assuming that it is able to indicate as a function of $(\mathrm{G} / \mathrm{v})$ from eq. (1) about $c_{1}$, the analyzed result is shown to FIGURE 6. The relation is followed as

$$
\mathrm{c}_{1}=1.35 \times 10^{-41}(\mathrm{G} / \mathrm{v})^{9.00}+88.7 \quad(\mathrm{R}=0.945)
$$

$\mathrm{R}=0.945$ and it is a fairly good correlation. Because it becomes $\mathrm{c}_{1} \rightarrow \infty$ in the case of wind velocity $\mathrm{v}=0$ (calm), it needs to be calculated as the value about 0.01 .

Next, it is able to indicate as

$$
\mathrm{c}_{1}=\left[\log \mathrm{e}\left\{\mathrm{m}_{1} \mathrm{a}_{1} \mathrm{~m}_{2}(\mathrm{G}+\mathrm{n} \cdot \varepsilon)\right\}\right] / \mathrm{a}_{1}
$$

as shown in eq. (1-f), and then 


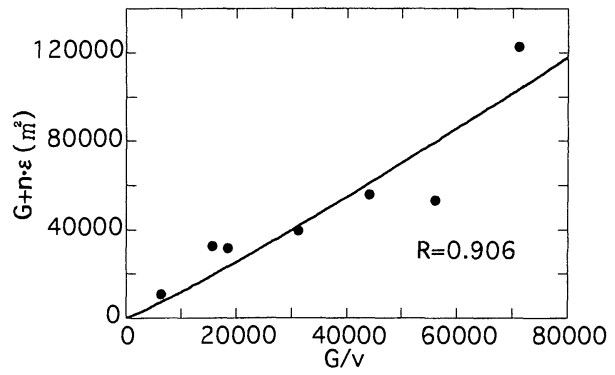

FIGURE 4 Relation between $\mathrm{G}+\mathrm{n} \cdot \varepsilon$ and $\mathrm{G} / \mathrm{v}$

$$
\exp \left(a_{1} \cdot c_{1}\right) /(G+n \cdot \varepsilon)=m_{1} \quad a_{1} m_{2}
$$

It is able to indicate like FIGURE 7 from TABLE 3 and $\mathrm{R}=0.998$. It has been understood that $c_{1}, a_{1}$ and also $(G+n \varepsilon)$ is followed as

$$
\exp \left(\mathrm{a}_{1} \cdot \mathrm{c}_{1}\right) /(\mathrm{G}+\mathrm{n} \cdot \varepsilon)=58.3 \mathrm{a}_{1}{ }^{2.85} \quad(\mathrm{R}=0.998)
$$

If the value of TABLE 2 is substituted in eq. (3) eq. (5) about each survey area, $(\mathrm{G}+\mathrm{n} \cdot \varepsilon)$, $\mathrm{a}_{1}$ and also $\mathrm{c}_{1}$ can be gotten. TABLE $4 \sim$ TABLE 6 were indicated these coefficient every $(\mathrm{G}+\mathrm{n} \cdot \varepsilon), \mathrm{a}_{1}, \mathrm{c}_{1}$ about each survey area. FIGURE 8 is an example of survey area 1.

As it is understood from TABLE 4 that inside values of parentheses needs to be used for a prediction value of $(\mathrm{G}+\mathrm{n} \cdot \varepsilon)$ in survey area 1,4 and also 8 .

$\mathrm{a}_{1}$ is about $0.0114 \sim 0.0626$ of TABLE 5 (average wind velocity about $1.30 \mathrm{~m} / \mathrm{s}$ of all survey areas). In the case of the Saganoseki real fire experiment[3, 5], $\mathrm{a}_{1}=0.143 \sim 0.460$ under $\mathrm{G} \fallingdotseq 150 \mathrm{~m}^{2}$ and $\mathrm{a}_{1}=0.150$ under $\mathrm{G}=804 \mathrm{~m}^{2}$ (the average wind velocity was about 1.8 $\mathrm{m} / \mathrm{s}$ ). When we observe it in comparison with $\mathrm{a}_{1}$ at the time of the fire experiment of Saganoseki, it becomes small with about $1 / 13 \sim 1 / 7$. It seems to be the reason that the completely destroyed rate is about $30 \sim 70 \%$ and that average wind velocity was rather than small.

Coefficients of correlation between estimation values and measurement values of burnout area are survey area 1(0.979), survey area $2(0.755)$, survey area $3(0.996)$, survey area 4 (0.897), survey area 5(0.999), survey area $6(0.961)$ and also survey area $8(0.993)$ and coefficient of a whole is 0.984 .

A prediction model that substituted eq. (3), eq. (4) and also eq. (5) in eq. (1) like this is shown as in eq. (7).

$$
A=\frac{G+n \cdot \varepsilon}{1+\exp \left\{-a_{1} \cdot\left(x-c_{1}\right)\right\}}-\frac{G+n \cdot \varepsilon}{1+\exp \left(a_{1} \cdot c_{1}\right)}
$$




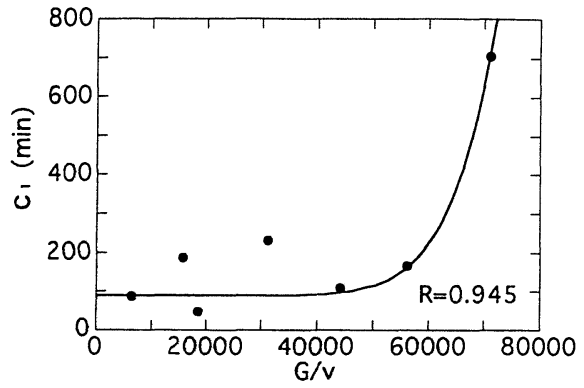

FIGURE 6 Relation between $c_{1}$ and $\mathrm{G} / \mathrm{v}$

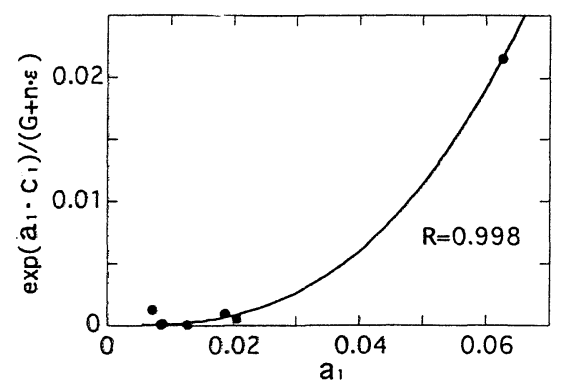

FIGURE 7 Relation between $\exp \left(\mathrm{a}_{1} \cdot \mathrm{c}_{1}\right) /$ $(\mathrm{G}+\mathrm{n} \cdot \varepsilon)$ and $\mathrm{a}_{1}$

TABLE $3 \mathrm{G}+n \cdot \varepsilon, \mathrm{a}_{1}, \mathrm{c}_{1}$ and $\mathrm{R}$ of each survey areas

\begin{tabular}{|c|c|c|c|c|}
\hline $\begin{array}{l}\text { Survey } \\
\text { area }\end{array}$ & $\begin{array}{l}\text { Value of } \\
G+n \varepsilon\end{array}$ & $\begin{array}{l}\text { Value of } \\
a_{1}\end{array}$ & $\begin{array}{l}\text { Value of } \\
c_{1}\end{array}$ & $\begin{array}{l}\text { Multiple correlation } \\
\text { coefficient } \mathrm{R}\end{array}$ \\
\hline 1 & 122820 & 0.0071417 & 706.700 & 0.944 \\
\hline 2 & 39445 & 0.0087452 & 232.830 & 0.998 \\
\hline 3 & 31872 & 0.0084954 & 46.654 & 0.999 \\
\hline 4 & 32458 & 0.0186480 & 185.550 & 0.998 \\
\hline 5 & 55638 & 0.0127660 & 109.500 & 0.999 \\
\hline 6 & 53257 & 0.0205310 & 166.860 & 0.999 \\
\hline 8 & 10675 & 0.0626170 & 86.864 & 0.999 \\
\hline
\end{tabular}

TABLE $4(\mathrm{G}+\mathrm{n} \cdot \varepsilon)$ of each survey areas

\begin{tabular}{crlrl}
\hline $\begin{array}{c}\text { Survey } \\
\text { area }\end{array}$ & $\begin{array}{l}\text { Value of } \\
\mathrm{G}+\mathrm{n} \varepsilon\end{array}$ & $\begin{array}{l}\text { Value of } \\
\mathrm{a}_{1}\end{array}$ & $\begin{array}{l}\text { Value of } \\
\mathrm{c}_{1}\end{array}$ & $\begin{array}{l}\text { Multiple correlation } \\
\text { coefficient } \mathrm{R}\end{array}$ \\
\hline 1 & 122820 & $\mathbf{0 . 0 0 7 1 4 1 7}$ & 706.700 & 0.944 \\
2 & 39445 & $\mathbf{0 . 0 0 8 7 4 5 2}$ & 232.830 & 0.998 \\
3 & 31872 & $\mathbf{0 . 0 0 8 4 9 5 4}$ & 46.654 & 0.999 \\
4 & 32458 & $\mathbf{0 . 0 1 8 6 4 8 0}$ & 185.550 & 0.998 \\
5 & 55638 & $\mathbf{0 . 0 1 2 7 6 6 0}$ & 109.500 & 0.999 \\
6 & 53257 & $\mathbf{0 . 0 2 0 5 3 1 0}$ & 166.860 & 0.999 \\
8 & 10675 & 0.0626170 & 86.864 & 0.999 \\
\hline
\end{tabular}


TABLE $5 a_{1}$ of each survey areas

\begin{tabular}{llll}
\hline Survey & Value & \multicolumn{2}{l}{ Estimation Complete } \\
area & of & value & collapse \\
& TABLE3 & from eq.(4) rate
\end{tabular}

\begin{tabular}{llll}
\hline 1 & 0.0071417 & 0.0114 & 0.714 \\
2 & 0.0087452 & 0.0114 & 0.667 \\
3 & 0.0084954 & 0.0123 & 0.460 \\
4 & 0.0186480 & 0.0183 & 0.309 \\
5 & 0.0127660 & 0.0114 & 0.485 \\
6 & 0.0205310 & 0.0114 & 0.431 \\
8 & 0.0626170 & 0.0626 & 0.587 \\
\hline
\end{tabular}

TABLE $6 c_{1}$ of each survey areas

$$
\begin{array}{lc}
G+n \cdot \varepsilon=0.431\left(\frac{G}{v}\right)^{1.11} & (\mathrm{R}=0.906) \\
a_{1}=2.28 \times 10^{20}\left\{\frac{(1-D) \cdot v}{G}\right\}^{5.17}+ & 0.0114 \\
& (\mathrm{R}=0.973) \\
c_{1}=1.35 \times 10^{-41}\left(\frac{G}{v}\right)^{9.00}+88.7 & (\mathrm{R}=0.945)
\end{array}
$$

where, as for $\mathrm{G}: 10,000<\mathrm{G}<120,000 \mathrm{~m}^{2}$, wind velocity v: $0<\mathrm{v}<6 \mathrm{~m} / \mathrm{s}$, complete collapse rate $\mathrm{D}$ : $0.3<\mathrm{D}<0.7$.

It is difficult that statistics processing are carried out because the data number is small as of now, to incorporate each factor to a model, although it is conceivable that it should

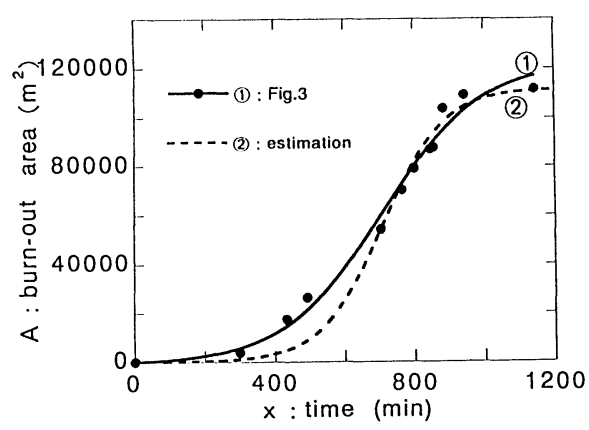

FIGURE 8 Correlation between estimation value and real value of survey area 1 
consider change of building structure, characteristic data of an area, for example a composition rate of effect/structure of the change/noninflammable range of a building-to-land ratio. Also, the consideration with regard to an effect of a fire fighting activity is conceivable as necessity and we are collecting such data at present. It is as a future theme that we should consider urban characteristics and fire fighting condition of the survey area in detail, although they are reflecting as in coefficients $n, \varepsilon, a_{1}$ and $c_{1}$ in eq. (7) as of now.

The relation between fire front length $(\mathrm{S}: \mathrm{m})$ and burn-out area $\left(\mathrm{A}: \mathrm{m}^{2}\right)$ of urban area fires in the Kobe Earthquake is shown to eq. (8).

$$
\mathrm{S}=1.11 \mathrm{~A}^{0.655} \quad(\mathrm{R}=0.958)
$$

where, burn-out area $\mathrm{A}$ is about $10,000<\mathrm{A}<120,000 \mathrm{~m}^{2}$.

The similar relation of usual fire in Kobe city is followed as

$$
\mathrm{S}=3.88 \mathrm{~A}^{0.545} \quad(\mathrm{R}=0.870)
$$

Eq.(8) is agreeing with eq.(9) very well like FIGURE 9.

Next, the average fire spread speed $(\mathrm{V}: \mathrm{m} / \mathrm{h})$ is indicated as $\mathrm{V}=(\mathrm{dA} / \mathrm{dx}) / \mathrm{S}$, where, the fire front length (S) of eq.(8) will be used. The spread speed $V$ of survey area 6 is shown in FIGURE 10.

The maximum fire spread speed of the measurement (Osymbol) and the average fire spread speed (dashed line) that analyzed from the fire spread movement figure, has been shown at FIGURE 10. The real line that was drawn 4.5 times the size of the average fire spread speed is also shown in FIGURE 10. Maximum value of the measurement is from about 4 times to about 5 of the average .

Now, the value of fire spread in this case is compared with the one of the big fire of the usual time in Japan. It is from $180 \mathrm{~m} / \mathrm{h}$ to $190 \mathrm{~m} / \mathrm{h}$ in the past big fire of Japan[2] when the wind velocity is $1.3 \mathrm{~m} / \mathrm{s}$, although the maximum value of fire speed is about $115 \mathrm{~m} / \mathrm{h}$ at the time of the Kobe earthquake in this time. Also, the average of maximum value of fire spread speed is from 80 to $100 \mathrm{~m} / \mathrm{h}$ in statistics value in the past, although the one of this time is from 40 to $50 \mathrm{~m} / \mathrm{h}[2]$. This reason is conceivable as a cause of a temporal change of building structure, collapsed etc..

\section{CONCLUSIONS}

1. The fire spread speed model that considered the complete collapse rate at the time of the Kobe earthquake has been indicated in eq.(7). Correlation coefficient of eq. (7) is 0.984 and the real fire data is agreeing fairly well. But the analysis does not take into account building density or other factor, so that the results would only appear to be relevant to urban situations very similar to Kobe city.

2. The parameter a1 is from 0.0114 to 0.0626 under $\mathrm{G} \fallingdotseq 10,000 \sim 120,000 \mathrm{~m}^{2}$, complete collapse rate $\mathrm{D} \fallingdotseq 30 \sim 70 \%$, average wind velocity $\mathrm{v} \fallingdotseq 1.3 \mathrm{~m} / \mathrm{sec}$, as shown in TABLE 3 and 


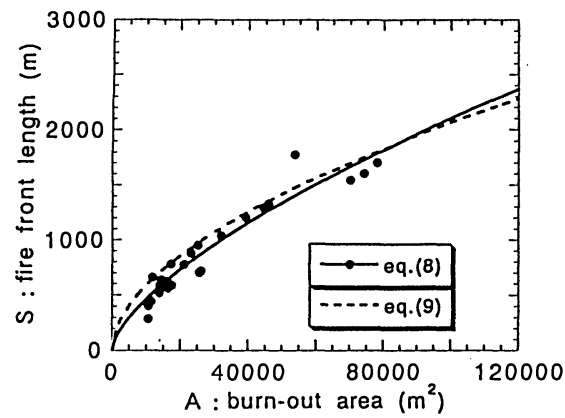

FIGURE 9 Relation between fire front length and burn-out area

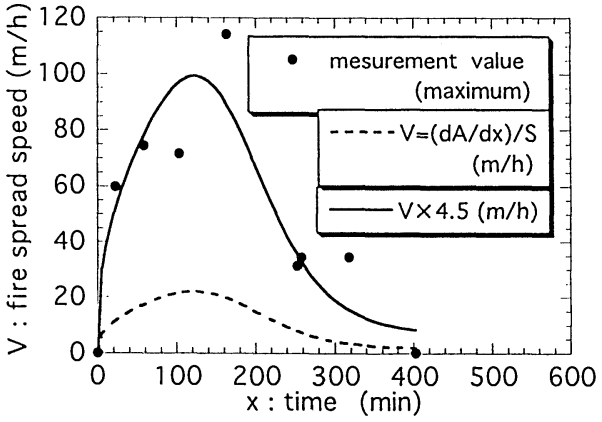

FIGURE10 Relation between fire spread and time of survey area 6

also TABLE 6. It is $1 / 13 \sim 1 / 7$ in comparison with a1 $=0.143 \sim 0.460$ of the experiment result of the real house group of Saganoseki $\left(\mathrm{G} \fallingdotseq 150 \sim 804 \mathrm{~m}^{2}, \mathrm{D}=0, \mathrm{v} \fallingdotseq 1.8 \mathrm{~m} / \mathrm{s}\right)$.

3. The fire front length of urban fire at the time of the Kobe earthquake has been able to indicate like FIGURE.10. Eq.(8) and eq.(9) are same for the most part. Therefore, the fire front length of the earthquake is not different from the one of the usual fire.

4. It has been shown that the fire spread speed $V$ can be gotten by burn-out area $A$, i.e. $d A / d x$ and fire front length $\mathrm{S}$. And in this study, the maximum fire spread speed of measurement is from about 4 times to about 5 times of the average .

\section{ACKNOWLEDGEMENTS}

We would like to thank Fire Research Institute, the Ministry of Home Affairs, Tokyo Fire Department and also especially Fire Department of Kobe city where the fire data of this research and useful comments were offered.

\section{REFERENCES}

1. Hamada, M. , Fire ,ed. Nakata, K. , Kyoritsu Publishers, 1969 (in Japanese)

2. Horiuchi, S. , New edition Architecture Fire Prevention, Asakura Publishers, 1994 (in Japanese)

3. Yasuno, K.,Namba,Y, A Basic Study on Fire Spread Formula of Houses Fire Used by Logistic Curve, Trans. of Architectural Institute of Japan , No. 311, pp.137-144, 1982 (in Japanese)

4. Yasuno, K. ,Namba,Y, A Basic Study on Fire Spread of Buildings, Bull. of Japanese Association of Fire Science and Engineering, Vol. 32, No1, pp.23-32, 1982 (in Japanese) 
5. Yasuno, K. ,Namba,Y, A Basic Study on Fire Spread Formula (Logistic Curve) of Wooden Buildings by Finite Difference Graphical Method, Trans. Architectural Institute of Japan , No. 325, pp.155-160, 1983 (in Japanese)

6. Yasuno, K. ,Namba,Y, A Basic Study on Effectiveness of Suppressing Building Fire by Water Application, Bull. of Japanese Association of Fire Science and Engineering, Vol. 32, No2, P57-65, 1982 (in Japanese)

7. Namba, Y., Yasuno, K, A basic study on Building Fire and Fire Fighting Water Carriage, Annual Meeting of Japanese Association of Fire Science and Engineering , P101-102, 1981 (in Japanese)

8. Yasuno, K. ,Namba,Y, A Basic Study on The Extinguishing and Water Damage area of TheUsual Building Fire, Journal of Stract. Engng. Architectural Institute of Japan, No.422, pp.135-143, 1991 (in Japanese)

9. Yasuno, K. ,Namba,Y, Water Supply Planning for Building Fire in Urban Area, Proc. of Japan Society of Civil Engineering , No. 425/N-14, P145-153, 1991 (in Japanese)

10. Yasuno, K. ,Namba,Y, Study on Fire Spread Formula and Necessary Volume of Water for Extinction, Bull. of Japanese Association of Fire Science and Engineering ,Vol. 20, No. 2, 1971 (in Japanese)

11. Namba, Y. , Yasuno, K, A Study on The Fire Spread Model of Wooden Buildings in Japan, 1st Inter. Symp. on Fire Safety Science, Gaithersburg, Md., p.881-890, 1985 (in English)

12. Tokyo Fire Department : Clarification and Countermeasure of Fire Spread of City Big Fire at the Time of Earthquake, 1985 (in Japanese)

13. Itoigawa, E. : Basic Study on Evaluation Method of Outbreak of Fire/Fire Spread Dangerous in Urban Area, Tokyo Institute of Technology Doctoral Thesis, 1990

14. Akaike, H. : Information Theory and an Extension of the Maximum Likelihood Principle, 2nd Inter. Symp. on Information Theory (Petrov, B. N. and Csaki,F. eds.), Akademiai Kiado, Budapest,1973 (in English)

15. Fire Research Institute, Ministry of Home Affairs, Government of Japan : Research Survey Report of Large-scale Fire Measurement by Real House Group, 1980(in Japanese)

16. Tanabe, K.," Error in Numerical Value Calculation", The Processing of Error of Statistical Data; Bit extra edition), Kyoritsu publishers, p.113-125, 1975 (in Japanese)

17. Fire Department of Kobe city : Record of Fire Fighting Activity of the Hanshin/Awaji Earthquake Disaster (Kobe City Area), P113, P149-161, Disaster Prevention Safe Public Corporation of Kobe city/Tokyo-horei publishers Co. Ltd., 1995 (in Japanese)

18. Faculty of Engineering, Kinki University and Fire Department of Kobe City : Optimum Fire Fighting Power Survey Report, 1985 (in Japanese)

19. Tokyo Fire Department : Fire Spread Movement Survey Report of City Big Fire Associated with Southern Hyogo Prefecture Earthquake, Disaster Prevention Department, Tokyo Fire Department, 1995 (in Japanese) 